\title{
O que se aprende com a mobilidade de smartphones?
}

\author{
What do you learn from smartphones mobility?
}

\section{Sandro Bortolazzo}

Resumo: Smartphones abrangem várias funcionalidades - telefonia, e-mails, dispositivo de áudio e vídeo, interação por meio de aplicativos - que têm operado transformações nas formas como os sujeitos se movimentam, aprendem e habitam os centros urbanos. Inscrita no referencial dos Estudos Culturais, este artigo é resultado de uma pesquisa exploratória que problematiza os usos de smartphones e certos deslocamentos no entendimento sobre aprendizagem. Assim, dois movimentos de investigação se interligam, sendo o primeiro uma exposição sobre a emergência de smartphones, e o segundo um exame das relações entre os sujeitos e um tipo de mobilidade operada por smartphones. Os resultados indicam um tipo de aprendizagem diante das telas ao estilo móvel, ensinando formas de ser sujeito na sociedade contemporânea.

Palavras-chave: Smartphones. Educação. Mobilidade.

Abstract: Smartphones reach a variety of features - telephony, e-mail, audio and video device, interaction via apps - that have been transforming the way subjects move, learn and inhabit urban centers. Inscribed under Cultural Studies framework, this article is the result of exploratory research that discusses the use of smartphones and some displacements in the understandings about learning. Thus, two research movements are interconnected, being the first an exhibition about the emergence of smartphones, and the second an examination of the relationships between subjects and a type of mobility operated by smartphones. Results indicate a type of learning in front of the mobile-style screens, teaching ways of being subject in contemporary society.

Keywords: Smartphones. Education. Mobility. 


\section{Introdução}

Stephen Hawking é considerado um dos físicos mais famosos desde Albert Einstein. No entanto, embora a substantiva contribuição intelectual do cientista ainda permaneça viva, o reconhecimento instantâneo por parte das pessoas se deu devido à adversidade física e à icônica cadeira motorizada com o qual se movimentou durante anos. Diagnosticado com uma doença neuronal motora, por décadas, o cientista utilizou da tecnologia para compensar as habilidades físicas declinantes, operando através de um sintetizador eletrônico que o dotou de uma voz rouca vastamente conhecida.

É notório que as ferramentas tecnológicas têm se apresentado enquanto elementos importantes ao desenvolvimento das sociedades e, muitas vezes, servindo para aprimorar a qualidade de vida de milhões de pessoas. Mesmo aqueles desprovidos das benesses de telefones celulares, aparelhos de televisão ou mesmo automóveis, ainda assim, utilizam luz elétrica ou consomem mantimentos - ambos distribuídos e gerenciados por sistemas interligados eletronicamente.

Dispositivos de bolso, a exemplo de smartphones, vêm se tornando interfaces que combinam uma série de funcionalidades: da telefonia padrão, de mensagens de texto, envio e recebimento de e-mails, da navegação na internet, das câmeras de vídeo, dos leitores digitais, dos consoles de jogos, dos dispositivos de áudio e vídeo, da interação por meio de aplicativos, dentre inúmeras outras. Como a pervasividade de smartphones tem transformado deslocamentos no entendimento sobre aprendizagem é o que desperta interesse neste estudo. Quer dizer, interessa pensar como a interação dos sujeitos junto ao toque sensível das telas tem operado novas formas dos sujeitos se movimentarem nos centros urbanos, hoje circunscrito à questão da mobilidade.
Inscrita no referencial teórico dos Estudos Culturais, esta pesquisa de natureza exploratória emerge a partir de um conjunto de questionamentos sobre os usos cotidianos de smartphones. A pesquisa constitui também parte do projeto de pósdoutorado financiado pela CAPES e conduzido no Institute for Culture and Society, (Western Sydney University) na Austrália.

A abordagem, assim, leva em consideração dois movimentos de investigação interligados. primeiro desenvolve uma exposição sobre a emergência de smartphones, e o segundo movimento investigativo examina as relações entre os sujeitos e um tipo de mobilidade operada pelas tecnologias móveis de smartphones. Para ambos intentos, o referencial teórico se apoia nas discussões de Verhoeff (2012), Richardson (2007), Lemos (2007, 2008), entre outros autores.

Os resultados apontam para um modo de habitar e se movimentar no mundo em que os usuários incorporam um objeto que exige adaptação social e somática. Isso significa que o uso de smartphones, além de ampliar a gama de meios comunicacionais presente na vida dos sujeitos, de certa forma, configuram um tipo de mobilidade diante das telas, reconfigurando significativamente as noções de aprendizagem.

\section{Imersão na tela: breve trajetória dos smartphones}

As relações dos sujeitos com as tecnologias sempre desempenharam papel significativo na produção dos sujeitos e das sociedades de forma geral. Em Foucault (2008), por exemplo, há uma articulação entre tecnologia, técnica e sociedade em Segurança, Território e População. Foucault (2008) identifica a tecnologia a partir de uma dimensão estratégica das práticas cotidianas. Quer dizer, as tecnologias se relacionam não apenas às formas como o mundo vem sendo experimentado e habitado pelos sujeitos, mas interroga quais seriam 
as condições impostas aos sujeitos para que "ele possa introduzir-se, funcionar e servir de nó na rede que nos rodeia (FOUCAULT, 2008, p. 30).

Assim, para tentar compreender a emergência de smartphones, é preciso levar em consideração duas questões latentes ao campo dos Estudos Culturais: a recusa de qualquer determinismo tecnológico e, ao mesmo tempo, a compreensão dos artefatos digitais enquanto conectados às práticas culturais de cada sociedade. Os aparatos tecnológicos nunca agem sozinhos, mas fazem parte do conjunto de elementos que dão forma às sociedades. Tomando McLuhan (1970), é possível argumentar que os sujeitos produzem as tecnologias ao passo que as tecnologias também acabam moldando e produzindo determinados tipos de sujeitos. McLuhan (1970) procurou evitar o determinismo tecnológico, embora nem sempre tenha sido cuidadoso com tal armadilha, e reconhece que cada ferramenta, do lápis aos computadores, apresenta usos prováveis que produzem ações e práticas nas sociedades.

Na mesma linha de raciocínio, para Williams (1975), a cultura é igualmente material, não está implicada somente nas formas enquanto vivemos, senão trata-se da própria vida. Isso significa que smartphones não somente instigam os modos pelas quais o mundo vem sendo vivenciado e experimentado, mas constituem e são os próprios produtos culturais e materiais das sociedades.

Antes considerados objetos do mundo corporativo, útil ao trabalho de executivos de grandes empresas, hoje a popularização dos telefones celulares é inconteste e, cada vez mais, indispensável à vida em sociedade. As versões smartphones já estão amplamente disponíveis, consumadas e, para utilizar uma expressão de Lemos (2007), são uma espécie de "tele tudo", "um dispositivo que é ao mesmo tempo telefone, máquina fotográfica, televisão, cinema, receptor de informações jornalísticas, difusor de e-mails e SMS
(...), GPS, tocador de música (MP3 e outros formatos), carteira eletrônica (...)" (idem, p.9).

Quando telefones celulares foram introduzidos pela primeira vez, a visão de alguém na rua falando para si mesmo era considerada cômica. As pessoas passaram, então, a falar em voz alta, certamente por algum motivo relacionado à sociologia da moda dos usuários de telefones celulares. Enquanto o incômodo de conversas unilaterais ainda persista, os sujeitos, de forma geral, assimilaram o dispositivo enquanto elemento do cotidiano e, aos poucos, foram aprendendo a utilizar os aparelhos de forma mais discreta e casual.

McCarthy (2011) relata que o primeiro smartphone foi produzido em 1992 pela IBM e que, além de uma tela sensível ao toque e um teclado próprio para redigir e receber mensagens de texto, apresentava a capacidade de enviar e-mails, fato impensável na época. No entanto, o termo smartphone só ganhou aderência ao vocabulário diário junto às empresas Ericsson e Nokia, essa última por ocasião do lançamento do modelo Nokia 9000, notório pelo elevado número de aparelhos comercializados.

No entanto, um dos mais significativos e importantes smartphones emerge no mercado em 2007 quando a Apple lança o primeiro iPhone. A empresa, de fato, tem gerado e mantido a tendência em termos de desenvolvimento de aparelhos, aplicativos, design e de navegabilidade diante das telas que permanecem como referência até hoje. Os modelos de iPhone, inclusive, inventam e reinventam formas de utilizar os smartphones e engendram novas e reconfiguradas intenções de consumo.

Um conceito de smartphone é análogo a um telefone celular, mas se distingue pela capacidade de executar tarefas similares a de um computador, com alusão ao processamento de dados através de um sistema operacional que opera softwares de terceiros, conhecidos como apps ou aplicativos. 
Zheng e Ni (2006) definem smartphones enquanto o resultado da convergência de um aparelho celular de operação normal com um PDA (Personal Digital Assistant). Verkasalo (2008), na mesma linha, define smartphones como dispositivos que permitem a interação entre os sujeitos por meio de aplicativos, aos moldes dos disponíveis em computadores tais como calculadora, browsers de navegação, visualizadores de documentos, etc. Lemos (2007) talvez tenha conseguido descrever com mais clareza o que vem a ser um smartphone, o que ele denominou de Dispositivos Híbridos Móveis de Conexão Multirredes ou DHMCM.

A denominação de DHMCM permite definilo melhor e com mais precisão. O que chamamos de telefone celular é um Dispositivo (um artefato, uma tecnologia de comunicação); Híbrido, já que congrega funções de telefone, computador, máquina fotográfica, câmera de vídeo, processador de texto, GPS, entre outras; Móvel, isto é, portátil e conectado em mobilidade funcionando por redes sem fio digitais, ou seja, de Conexão; e Multirredes, já que pode empregar diversas redes, como: Bluetooth e infravermelho, para conexões de curto alcance entre outros dispositivos; celular, para as diversas possibilidades de troca de informações; internet (Wi-Fi ou WiMax) e redes de satélites para uso como dispositivo GPS. (LEMOS, 2007, p.25)

A característica mais relevante no universo de smartphones é aquela relacionada ao acesso à internet, seja por redes sem fio de alta velocidade 3G (terceira geração) ou 4G (quarta geração), seja por Wi-Fi ou tecnologia bluetooth. Reside aí, segundo Hsiao e Chen (2015), um fator decisivo de distinção entre um smartphone e um telefone celular comum, ou seja, a possibilidade do acesso à internet. Os aplicativos para smartphones, por sua vez, dependem da rede, sendo, portanto, imprescindíveis a sua existência e continuidade.

Smartphones estão inseridos dentro de um conjunto de elementos enredados em comunicações instantâneas, avanços tecnológicos e todo um aparato mercantil englobando empresas como Apple, IBM, Microsoft, Sony, Google, Yahoo,
Facebook, Twitter, Instagram ou mesmo YouTube. Hoje, cabe igualmente enquadrar smartphones dentro de um universo de aplicativos que tem modificado modelos de negócio, a exemplo de Netflix, Spotify e Uber.

No início, os aplicativos mais baixados se concentravam junto às redes sociais. Hoje, os consumidores estão usando smartphones para uma infinidade de atividades. Há aplicativos para compras online, carteira eletrônica, passagens aéreas e hotéis; interação com amigos, familiares e colegas de trabalho; pedido de comida a tele entrega; consulta a trajetos de mobilidade por carro ou transporte público; estudo de outros idiomas; contagem de calorias, nutrientes, massa corporal, e assim por diante.

$\mathrm{Na}$ interação com smartphones e aplicativos, são sujeitos e objetos em operação, mas também um regime tecnológico digital colocado em circulação que, em certa medida, vai configurando transformações sociais, econômicas, culturais, políticas.

\section{Do espaço das telas à mobilidade: o que se aprende com smartphones?}

Para muitas pessoas dirigir um carro parece uma atividade fácil e automática. No entanto, conduzir um veículo envolve uma série de aprendizagens. Inicialmente é preciso aprender sobre a organização do espaço, operar com os limites de velocidade do veículo, a direção, os pedais, e assim por diante. Dentro do carro, o motorista precisa ajustar a postura, treinar e adaptar o corpo às formas como o automóvel se movimenta, familiarizando-se, assim, com a posição dos retrovisores, as distâncias entre os carros, dentre outras habilidades técnicas e corporais. Além disso, é preciso estar alfabetizado semioticamente com as placas de sinalização, os radares de controle, as câmeras de fiscalização, os semáforos, as faixas de segurança. Conscientemente, é necessário orientar 
o corpo para a lógica espacial e de movimento dos automóveis e seus arredores. Com certa prática, dirigir se torna habitual, uma vez que o corpo se acomoda à tal atividade. Dessa forma, o espaço e todos os aspectos relativos ao automóvel são incorporados como parte do repertório de habilidades proprioceptivas, ou seja, aspectos físicos e biológicos, materiais e culturais, memória e hábito se imbricam.

Processo similar ocorre com os usos de smartphones. Os telefones celulares não são simplesmente próteses ou ampliações dos sentidos humanos, mas atuam enquanto ferramentas que impactam os limites do corpo. É possível descrever os smartphones como um tipo de tecnologia móvel que engloba orientação visual, acústica e sensorial, exigindo, por assim dizer, variados modos de envolvimento, acomodação e adaptação por parte dos sujeitos.

Smartphones são recursos materiais da cultura contemporânea e, dentro da perspectiva dos Estudos Culturais adotada nesta pesquisa, também podem ser analisados como agentes na produção das subjetividades. Quer dizer, a relação dos sujeitos com smartphones se inscreve na intersecção de vários discursos - do mercado de consumo de artefatos tecnológicos; da multiplicação de aplicativos; das possibilidades do digital enquanto recurso pedagógico; das formas de entretenimento e lazer mediadas digitalmente.

Aparelhos celulares, por terem invadido diversos lugares de sociabilidade, também fazem parte do complexo de elementos que produzem formas de ser sujeito no presente. Ao encontro do que aponta Foucault (2004, p.238) "são as práticas concebidas ao mesmo tempo como modo de agir e de pensar que dão a chave de inteligibilidade para a constituição correlativa do sujeito [...]".

Em análise análoga, Richardson (2007) alerta que toda relação humano-tecnologia é igualmente uma relação corpo-ferramenta e, como tal, invoca certos modos de estar no mundo. As formas pelos quais os telefones celulares são segurados e manuseados, por exemplo, ressaltam apenas alguns dos aspectos que os diferenciam de outros dispositivos. Devido a portabilidade e miniaturização, constituem uma espécie de acessório anexo ao corpo, agora não mais apenas um objeto presente na mão, mas à mão e no bolso, ou seja, perto do corpo. Talvez o que diferencie smartphones de outros aparelhos como computadores seja a própria proximidade com seus usuários. Além dos telefones celulares estarem sempre com seus usuários, são artefatos portáteis, onipresentes, ou muito próximo do que McLuhan (1970) denominou de extensão dos sentidos do homem. Um aparato que de forma simbiótica estende a capacidade de comunicação.

Interações mediadas por aparelhos celulares vêm adquirindo centralidade nas práticas sociais cotidianas e hoje qualquer distinção significativa entre espaço físico e virtual que forneça um sentido estável de orientação já não é mais possível. Manovich (2001) reconhece que as telas digitais são os principais agentes de distinção e mediação nas sociedades, tendo se tornado um dos principais elementos pelas quais a cultura vem sendo produzida em países tecnologicamente avançados.

As telas de telefones celulares, de meras ferramentas de telefonia móvel, se transformaram em filtros que começam a suprir e, muitas vezes, substituir a tela do cinema, da televisão, das páginas de livros, etc.

Além de elementos onipresentes, as telas de smartphones são um convite ao engajamento. São objetos, tecnologias, aparatos, máquinas de visão, plataformas. São igualmente dispositivos tecnológicos, interface, superfície plana posicionada em arranjo (3D, ou mesmo 4D) de tempo e movimento, uma metáfora de representação. São, sobretudo, sensíveis ao toque, o touchscreen. Uma tela tátil implicitamente conjectura uma relação imediata entre visualização, navegação e atuação (movimento). A visualidade na 
tela determina o que se enxerga e como se enxerga (VERHOEFF, 2012).

Ao contrário da tela cinematográfica ou televisiva, nos smartphones, ela pode ser tocada, interpelando os usuários a se movimentar e navegar virtualmente. É como se as telas atuassem enquanto elemento cognitivo; uma nova maneira de compreender o espaço; um tipo de visualidade ativada pela mão; uma relação através do qual a visão se torna tátil.

A tecnologia touchscreen convoca os sujeitos a tocar para, então, ver, mesclando a experiência do sentir com a de enxergar. A visualização, dessa forma, não é mais uma questão apenas de olhar, tampouco de receber imagens, mas implica movimento e interação. Trata-se de um tipo de navegabilidade em que os dedos controlam qualquer atividade. Logo, é possível navegar por entre álbuns de fotografias, folhar páginas de livros, enviar e receber e-mails, ampliar ou reduzir o tamanho de uma página, tudo com o auxílio das mãos.

Na perspectiva de Verhoeff (2012), o espaço da tela não é literalmente o mesmo espaço da mão que segura o telefone. A experiência do espaço pode ser analisada em termos de certa continuidade espacial dos olhos, da mão, da tela. Em resposta às tecnologias anteriores, "a mobilidade de smartphones é, portanto, melhor entendida como a extensão espacial não além da tela, mas antes dela (entre o olho e a tela)"(idem, 2012, p.90). As telas de smartphones são mais intimistas que uma tela distante, mais individual que uma tela grande e mais intuitiva que uma tela que se encontra apartada.

De fato, é a portabilidade dos aparelhos celulares que concretiza a continuidade entre os espaços. Uma continuidade que é espacial, mas inevitavelmente também temporal e corporal. O que talvez seja distinto nos telefones celulares é o fato da mobilidade ser multifacetada; ela envolve a tela, o usuário, a imagem, a navegabilidade, o movimento, o toque e o processo de transformação do e no espaço. Um exemplo dentro deste cenário são as mídias locativas ou tecnologias e aplicativos de geolocalização (LEMOS, 2008). Elas permitem certa realidade aumentada, um mapeamento e localização que produzem um território de informações em fluxo contínuo, interseccionando espaço físico e virtual.

Aplicativos de localização tais como Google Maps, Waze, entre outros, têm invadido o espaço urbano, proporcionando aos sujeitos outras experiências. Esses aplicativos mapeiam e identificam o entorno dos usuários através de sistemas GPS (sistema de posicionamento global), facilitando a locomoção das pessoas, seja via transporte público, seja por meio de taxi, automóveis privados ou mesmo andando. O aplicativo Waze, por exemplo, tem sua base de dados atualizada constantemente, já que é construída e compartilhada por usuários, a exemplo de uma rede social, e alimentada pelos próprios membros que vão informando sobre buracos nas pistas, obras, trânsito interrompido, barreiras policiais, e assim por diante. Este tipo de aplicativo leva à discussão de outro elemento presente junto a interação com smartphones, a questão da presença.

O envolvimento com dispositivos digitais visuais adentra um nível perceptivo e fenomenológico capaz de alterar os sentidos de presença. Para Steuer (1992), o termo presença pode ser considerado enquanto a experiência dos sujeitos em um ambiente físico ou, de forma geral, a sensação de estar em um determinado ambiente. No entanto, quando tecnologias móveis de interação são introduzidas nesta equação, as noções se transmutam. Ao navegar por um aplicativo como Waze, simultaneamente dois ambientes distintos estão dispostos, o ambiente físico no qual o corpo está localizado e o espaço conceitual ou interacional pelo qual se interage (STEUER,1992). Esse sentido alterado de presença se torna cada vez mais presciente. Quer dizer, onde 
o corpo está, mas também um "entre espaço" em que o corpo está e onde outra pessoa/lugar está; não um espaço físico, mas conceitual (LISTER et al., 2009). Isso significa que, a um simples toque na tela, os sujeitos são conduzidos a incorporar a tecnologia como algo que o transporta de um lugar a outro, mas que igualmente movimenta as relações sociais.

Para Urry (2007), hoje há um tipo de sociologia, uma movimentação social que encontra terreno fértil na mobilidade, em contraste ao tipo de morfologia fundado nas sociedades fixadas territorialmente. As tecnologias móveis, de alguma forma, vêm capacitando e adaptando os sujeitos a viver em mobilidade. Isso ocorre, por exemplo, quando inconsciente ou conscientemente pesquisas são realizadas junto ao navegador do celular ou mesmo quando se recorre aos aplicativos de transporte para guiar e apoiar na decisão da melhor rota a seguir.

A mobilidade diz respeito igualmente às novas experiências dos sujeitos com smartphones; engendra outros modos de estar no mundo; engloba um tipo de estilo de vida; produz novos modelos de negócios que buscam apoio na mobilidade tais como os de aplicativos para meios de transporte, acesso a livros, filmes e músicas. A interação com smartphones estimula uma maneira de conduzir a vida de forma móvel. Exemplos expoentes estão nos milhares de aplicativos destinados a inúmeras atividades - compras, consulta a extratos bancários, pagamentos de contas, leitura de notícias, previsão do tempo, relacionamentos, comunicação instantânea, etc. Os aplicativos são produzidos para que os consumidores os utilizem em mobilidade. Chamar um taxi está a três toques da tela. Mais alguns toques e a refeição está na porta de casa, as contas pagas, e uma lista de músicas disponíveis. Os aplicativos também monitoram a saúde, reservam viagens, ensinam idiomas estrangeiros, mostram a temperatura e o fuso horário em diversos lugares do mundo.
Nesse sentido, seria possível conjecturar a emergência de um tipo de aprendizagem ao estilo móvel que se dá diante das telas e que ocorre a qualquer hora e em qualquer lugar. Não se trata de uma simples mudança de serviços voltados à educação institucionalizada, a exemplo das plataformas ou ambientes online, mas de toda uma infraestrutura que dialoga com a mobilidade. Quer dizer, uma aprendizagem que se conecta ao capitalismo informacional (CASTELL, 1999), com métodos que atendem à escolha individual, muitas vezes, pautada pela utilização imediata, atualizada, mas sobretudo, ininterrupta. Bernstein (2001), na mesma linha argumentativa, afirma que governos, meios de comunicação e os próprios sistemas de ensino superior estão propagando a ideia de uma aprendizagem sem fim, uma aprendizagem ao longo da vida, ou na vertente do que Williams (1996) referiu como educação permanente, uma força educacional de toda a experiência social e cultural.

De uma sociedade centrada no ensino, exclusivo dos espaços das escolas e universidades, a ênfase contemporânea parece estar voltada à aprendizagem, como referido por Noguera-Ramirez (2011). Tal deslocamento sinaliza o quanto as aprendizagens se dão em variados espaços e por meios de muitos artefatos que ultrapassam os limites da escola. "Se na Modernidade se inaugurou, uma sociedade de ensino", hoje ela estaria sob a forma "de uma sociedade de aprendizagem" (idem, 2011, p.230).

Diversos aplicativos para smartphones vêm estimulando novos hábitos, condutas, comportamentos, reestruturando aprendizagens que, agora, ocorrem ao ritmo de cada um. O conhecimento, assim, é enquadrado pelo agenciamento e direção do próprio sujeito em contraste às práticas usualmente empregadas no ensino institucionalizado. Inclui-se no complexo de elementos que dão visibilidade a este tipo de aprendizagem móvel empresas como Google, Yahoo e Facebook que, de alguma maneira, têm 
alterado as formas como os sujeitos acessam e interagem com as informações. Outro exemplo que corrobora a ideia dos sujeitos enquanto responsáveis pela própria aprendizagem são as plataformas de tecnologias móveis imbricadas diretamente à educação na área do ensino superior, que além dos cursos EAD, encontrou no MOOCs (Massive Open Online Courses) uma oportunidade de oferecer cursos online gratuitamente. Três grandes empresas, a edX (iniciado por Harvard e pelo Massachusetts Institute of Technology), a Coursera (da Universidade de Stanford) e a Udacity (também com raízes em Stanford) monopolizam o mercado. No Brasil, uma mesma frente toma corpo na Universidade de São Paulo (USP) com alguns cursos e aulas disponíveis.

Além disso, formações profissionais de curto prazo, orientada à demanda do mercado, muitas vezes obtidas em cursos flexíveis (geralmente online) e que apostam na capacidade autodidata dos estudantes têm sido mais sedutoras e ganham mais visibilidade do que uma formação à moda antiga. Tal deslocamento tem produzido sujeitos aptos a lidar com a mobilidade, velocidade, incertezas e com as constantes adaptações e atualizações. Nas possibilidades de acesso a milhões de informações a um simples toque na tela, os sujeitos são conduzidos a incorporar a tecnologia de smartphones como algo que movimenta as relações sociais, transitando entre conteúdos que vão desde entretenimento, política, esporte até saúde e economia.

Cabe lembrar ainda que, cada sociedade, produz sujeitos que fazem o sistema social funcionar, ou seja, é preciso compreender que tipo de sujeito este regime tecnológico quer formar. Talvez esse tipo de aprendizagem contínua e móvel venha sendo particularmente enaltecida em uma lógica neoliberal que responsabiliza e identifica os sujeitos como capazes de potencializar habilidades e competências por conta própria. Muitas das plataformas móveis de ensino - dos cursos EAD,
MOOC, mas também dos aplicativos que pretendem ensinar idiomas, engendrar cuidados com a saúde e alimentação - atuam enquanto um meio no qual os sujeitos passam a investir sobre sua própria vida. No entanto, para que esse tipo de aprendizagem ocorra, os sujeitos precisam estar aptos a viver e aprender com a mobilidade. A mobilidade, dessa forma, passa a ser uma condição da vida contemporânea.

Assim, os alvos de aplicativos de smartphones que estimulam aprendizagens móveis são sujeitos que habitam e se constituem nos espaços atrelados ao digital, à conexão ubíqua e móvel. Os sujeitos do presente são sujeitos às condições culturais do tempo presente. Por exemplo, a invenção de um modo provisório, instantâneo, cambiante e efêmero de viver e aprender exige, cada vez mais, aprendizagens que compreendam as dinâmicas sociais.

Enquanto um artefato físico e móvel, mas também disposto como uma plataforma repleta de aplicativos que fornecem aos sujeitos outras formas de habitar o mundo e de, até mesmo, representar aspectos de suas vidas (sociais, profissionais, políticas e até privadas), smartphones acabam modulando e orientando certos tipos de aprendizagem que regem novas sensibilidades no mundo contemporâneo. A ascensão das atividades desenvolvidas a partir de aplicativos faz dos smartphones um repositório cada vez mais importante de interação, cultura, memória e aprendizagem.

Hoje, o conhecimento, por exemplo, está descentralizado e pode ser acessado de qualquer lugar e por qualquer pessoa através das redes de informações inscritas em smartphones. A informação é universal, o acesso é universal, o conhecimento, de certa forma, também se torna universal. Onde quer que esteja, haja vista as possiblidades de acesso à internet, é possível verificar fatos, consultar teorias, compartilhar fotos, lugares, comunicar-se instantaneamente por texto, 
áudio e vídeo. Assim como os meios de transportes afetaram a percepção dos sujeitos em relação à velocidade, os usos de smartphones, na mesma linha de pensamento, sugerem distintas formas de circulação de conhecimento e outras formas de aprendizagem.

\section{Considerações}

O que se aprende com a mobilidade de smartphones? Certamente, a invasão desses aparelhos engendrou novas dinâmicas sociais que vem operando transformações nos modos como os sujeitos conduzem suas vidas, inclusive permitindo outras formas de realizar atividades cotidianas - da comunicação com familiares às aprendizagens.

A mobilidade tem avançado em muitas frentes: dos primeiros trens a vapor, metrôs, bondes e automóveis às redes de alta velocidade e linhas aéreas internacionais. Os usos de smartphones constituem apenas mais um dos elementos materiais contemporâneos que se encontram espacialmente organizado para operar em mobilidade.

As marcas operadas por artefatos digitais têm feito repercutir também a ideia de aprendizagem enquanto algo volátil, efêmero, ininterrupto e sempre em constante atualização. Aprendizagens que nunca cessam, inacabadas, ao estilo móvel e personalizadas. Dessa forma, a interação dos sujeitos com smartphones poderia ser analisada enquanto uma escolha em termos de estilo de vida engendrada constantemente por uma sociedade que investe pesado em material tecnológico. Tratase de uma combinação de artefatos, interesses e estilos de vida produzidos quando em contato com as possibilidades oferecidas pelas tecnologias móveis.

\section{Referências}

BERNSTEIN, Basil. From pedagogies to knowledges. In Morais, A., Neves, I., Davies, B. and Daniels, $H$. (eds). Towards a sociology of pedagogy: the contribution of Basil Bernstein to research. New York, Peter Lang, 2001.

CASTELLS, Manuel. A Sociedade em Rede. Trad. Roneide Venâncio e Jussara Simões. São Paulo: Paz e Terra, 1999.

FOUCAULT, Michel. Ditos \& Escritos V: ética, sexualidade, política. Tradução de E. Monteiro; I. A. D. Barbosa. 1. ed. Rio de Janeiro: Forense Universitária, 2004. 392 p.

FOUCAULT, Michel. Segurança, Território, População. São Paulo: Martins Fontes, 2008.

HSIAO, Ming-Hsiung; CHEN, Liang-Chun.-C.Smart phone demand: An empirical study on the relationships between phone handset, Internet access and mobile services. Telematics and Informatics, V.32, n.1, 2015, p.158-168.

LEMOS, André. Comunicação e práticas sociais no espaço urbano: as características dos Dispositivos Híbridos Móveis de Conexão Multirredes (DHMCM). Comunicação, Mídia e Consumo. Consumo, vol,4, n.10, São Paulo, 2007, p. 23-40.

LEMOS, André. Mídias locativas e territórios informacionais. In: ARANTES, P.; SANTAELLA, L. (Org.). Estéticas tecnológicas. São Paulo: PUC/SP, 2008.

LISTER, Martin; DOVEY, Jon; GIDDINGS, Seth; GRANT, Iain; KELLY, Kieran. New Media: a critical introduction. New York: Routledge, 2009.

MANOVICH, Lev. The Language of New Media. Cambridge, MA: MIT Press, 2001.

MCCARTY, Brad. The History of the Smartphone. $2011 . \quad$ Disponível em: <http://thenextweb.com/mobile/2011/12/06/the -history-of-the-smartphone/>. Acesso em: 10 fev. 2019

McLUHAN, Marshall. Os meios de comunicação como extensões do homem. Trad. Décio Pignatari. São Paulo: Cultrix, 1970.

NOGUERA-RAMÍREZ, Carlos Ernesto. Pedagogias e governamentalidade ou Da Modernidade como uma sociedade educativa. Belo Horizonte: Autêntica Editora, 2011. 
RICHARDSON, Ingrid. Pocket Technospaces: the Bodily Incorporation of Mobile Media Continuum: Journal of Media \& Cultural Studies. Vol. 21, No. 2, June 2007, p. 205-215.

STEUER, Jonathan. Defining Virtual Reality: Dimensions Determining Telepresence. Journal of Communication. v.42. n.4, ABI/INFORM Global, 1992 pg. 73 -93.

URRY, John. Mobilities. London: Polity Press, 2007.

VERHOEFF, Nanna. Mobile Screens: The Visual Regime of Navigation. Amsterdam: Amsterdam University Press, 2012.

VERKASALO, Hannu. Contextual patterns in mobile service usage. Personal and Ubiquitous Computing, V.1, n.5, 2008, p. 331-342

WILLIAMS, Raymond. Technology and Cultural Form. Londres: Shocker Books, 1975.

WILLIAMS, Raymond. Preface to second edition. Communications. 2nd Edition. London, Chatto and Windus, 1996.

ZHENG, P; Ni, L.Mheng. Spotlight: the rise of the smart phone. IEEE Distributed Systems Online, 2016. 